\title{
Comprehensive management of severe epilepsies in small countries with limited resources
}

\author{
Igor Mihael Ravnik ${ }^{1,3}$, Natalija Krajnc ${ }^{1,3}$, Mirjana Benedik Perković ${ }^{1}$, David Gosar ${ }^{1}$, Andrej Vranič
}

\begin{abstract}
INTRODUCTION
High professional expertise organized in multidisciplinary teams is needed to provide comprehensive epilepsy care. In Europe, 54 million people live in 24 countries with a population of less than 5 million and 12.5 millions live in countries with a population of less than 3 million. Adjusted solutions are needed for severely affected people with epilepsy in small health systems.
\end{abstract}

Living with epilepsy in a small country is a unique challenge for the patient, and so is implementing comprehensive care for people with epilepsy by health providers. Small populations require adjusted systems of care, often hard to realize due to limitations in economy and politics. Small population also means fewer patients referred and limited professional expertise that may adversely affect the quality of care. National languages spoken by small populations make use of foreign facilities difficult. Linguistic issue becomes even more important when neuropsychological and psychiatric problems are dealt with outside the area exclusively depending on one language. There is also a risk to neglect patients affected by rare syndromes requiring specific treatments. Comparing models of practice may be a useful exercise: systems of care extrapolated from large to small populations may not be most appropriate. Models effective in small health systems may at times be applicable to larger populations.

\section{METHODS}

Expert team estimate of trends in comprehensive pediatric and adolescent epilepsy care over the last decades was used to illustrate solutions in health care in a small population of 2 million on the example of Slovenia.

\section{RESULTS}

Cumulative incidence of epilepsy was 4.58/1000 in 1988 (age 0-18 years) (1), nowadays meaning about 2400 patients with epilepsy, 600-800 with resistant epilepsy and about 10 000 patients "across the epilepsy spectrum".

Three of most challenging issues in comprehensive epilepsy care in small populations are considered to be the ones related to: (a) surgically amenable resistant epilepsies; (b) psychosocial comorbidity; and (c) rare epileptic disorders.

\section{Patients with difficult-to-treat resistant epilepsies and epilepsy surgery}

Lesional neurosurgery has been performed in Slovenia for all age groups. As the population is too small to develop own pediatric epilepsy surgery, it is performed in quaternary centers abroad. During 18 years of weekly tertiary multidisciplinary expert team meetings, more than 800 patients have been discussed, among which the phase I presurgical assessments allowed selecting candidates for surgery, resulting in 70 referrals and 55 surgeries performed abroad (2). Patient mobility has been supported by National Health Insurance covering all medical costs. Volunteer accompaniment projects have been organized at the nongovernmental level (by the Slovenian Chapter of International League Against Epilepsy and International Bureau for Epilepsy) to facilitate care in foreign-speaking institutions. Recently, National Health Insurance has started covering specific activities of mobile professionals for the most demanding cases.

\footnotetext{
'Centre for Epilepsy, Department of Pediatric Neurology, University Children's Hospital, University Medical Centre Ljubljana, Ljubljana, Slovenia ${ }^{2}$ Department of Neurosurgery, University Medical Centre Ljubljana, Ljubljana, Slovenia

${ }^{3}$ Slovenian League against Epilepsy, Chapter of International League Against Epilepsy, Ljubljana, Slovenia
}

\section{Correspondence to:}

Igor Mihael Ravnik, Centre for Epilepsy, Department of Pediatric Neurology, University Children's Hospital, University Medical Centre Ljubljana, Zaloška cesta 2, Ljubljana, SI-1000, Slovenia, e-mail: iravnik@yahoo.com

Primljeno/Received: 10. 9. 2014., Prihvaćeno/Accepted: 3. 10. 2014. 
Priority goals are fund raising for staffing and specific professional education, formally establishing specific structures (Epilepsy Monitoring Unit, Tertiary Epilepsy Program) and systematic multidisciplinary work (also to include profiles not yet regularly participating in the teams: psychiatrist, neurosurgeon), as well as recognition of additional workload in collaborative cross-border patient management.

\section{Patients with psychosocial comorbidity}

An effective model combining hospital work with non-governmental networks in the community in the past proved more successful than the recent less integrated system of mental health services. Critical issues are the lack of interest in neuropsychiatric issues of epilepsy since neurology and psychiatry have been separated, the lack of dedicated professional inputs in the psychosocial domain, and no institution or program available for neurological patients with severe psychiatric comorbidity, especially if accompanied by adverse social situations.

Priority goals are structuring comprehensive teams, also at regional levels, and strengthening networking of available facilities, including out-reach activities from tertiary level (3).

\section{Patients with rare epileptic disorders}

Numbers of cases diagnosed in Slovenia roughly correspond to published data. Seven patients have been diagnosed with Dravet syndrome, 5 patients with Landau Kleffner syndrome, 5 patients with Unverricht-Lundborg disease, 4 patients with ring 20 chromosome syndrome, 1 patient with hypothalamic hamartoma, and 1 patient with Gastaut Geschwind syndrome. They all have been managed locally with second opinions and consultation with quaternary centers. Priority goal is fund raising for regular professional update and collaborative work on rare diseases (4).

\section{CONCLUSIONS}

Problems related to comprehensive epilepsy pediatric care in a small country do not differ epidemiologically from those in large populations. However, they require adjusted approaches making use of all available professional and non-governmental resources in the country. Cross-border collaboration is necessary among teams from small countries and quaternary centers of excellence. Specific expertise needs to be cultivated in postgraduate education for doctors and other medical and paramedical professions related to specific areas of competence. The positive experience stemming from the Slovenian model, quite unique in blending institutional with professional and lay non-governmental inputs in patient care, supports the need to promote greater patient empowerment to facilitate goal oriented changes in the health system.

Collaborative research and developmental projects and practical models of care to link neighbor or culturally/linguistically closer health systems from small countries, especially in the field of resistant surgically amenable epilepsies, psychosocial comorbidity and rare epileptic syndromes, should be considered as a means to sum up patient numbers, to increase and share quality of expertise in patientfriendly, safe and highly professional networks.

\section{REFERENCES}

1. Ravnik IM, Paro D, Tivadar I, Panjan B. Epidemiologie descriptive des epilepses des enfants dans la region sanitaire de Ljubljana. In: Jallon P, ed. Epidemiologie des epilepsies. London Paris: John Libbey; 1988:71-81.

2. Krajnc N, Ravnik IM, Gosar D, et al. Surgical management of paediatric onset epilepsies from Slovenia. Epileptic Disord. 2009;11;174.

3. Maček J, Ravnik IM. Comprehensive management of children and adolescents with epilepsy and psychiatric co-morbidity (Slov). In: Kržišnik C, Battelino T, ur. Izbrana poglavja iz pediatrije. Medicinska fakulteta Univerze v Ljubljani. 2012:121-9.

4. Perković Benedik M, Župančič N, Rener Primec Z, Krajnc N, Oražem J, Ravnik IM. Difficult to manage paediatric epileptic seizures and syndromes in children and adolescents (Slov). Slov Pediatr. 2010;17 (Suppl 1):185-92. 